\title{
Effects of Carded and Combed Yarn on Pilling and Abrasion Resistance of Single Jersey Knit Fabric
}

\author{
Ayesha Siddika ${ }^{1}$, Md. Nasir Uddin ${ }^{2}$, Mohammad Abdul Jalil $^{3}$, \\ Nur Nahar Akter ${ }^{4}$, Kowshik Saha ${ }^{5}$ \\ ${ }^{1,3}$ Textile Engineering Department, Khulna University of Engineering \& Technology, Bangladesh \\ ${ }^{2,5}$ Textile Engineering Department, Northern University Bangladesh, Bangladesh \\ ${ }^{4}$ Department of Apparel Manufacture \& Technology, BGMEA University of Fashion \& Technology.
}

\begin{abstract}
Pilling and abrasion are very important factors that affect the knitted fabric property greatly. In this experiment, $30 \mathrm{Ne}$ carded and combed yarns were used to make single jersey knitted fabric. Then abrasion resistance and pilling tendency were checked for both fabrics made from carded and combed yarn. For pilling, ISO 12945 - I \& ISO 12945 - 2 methods and for abrasion, ISO 12947 - 2, 3, 4 methods were conducted. Finally, it has been found that abrasion resistance and pilling performance are lower in fabric (carded yarn) than in fabric (combed yarn).
\end{abstract}

Keyword: Abrasion, Carded Yarn, Combed Yarn, GSM, Pilling.

\section{Introduction}

The demand of knit fabric is increasing day by day. Both carded and combed yarns are used to produce knit fabric. A yarn produced from fibers that have been carded but not combed is known as card yarn. On the other hand, the yarn produced from fibers that have been combed is known as combed yarn. In this process, the fibers are arranged in highly parallel form and additional short fibers are removed, producing high quality yarn with excellent strength, fineness and uniformity [1]. In addition, a yarn made of combed cotton fiber needs less twist than carded yarn [2]. There are mainly four basic weft knitted fabrics such as plain fabric or single jersey fabric, rib fabric, interlock fabric and purl fabric [3]. Among these fabrics, single jersey knit fabric is used for this study.
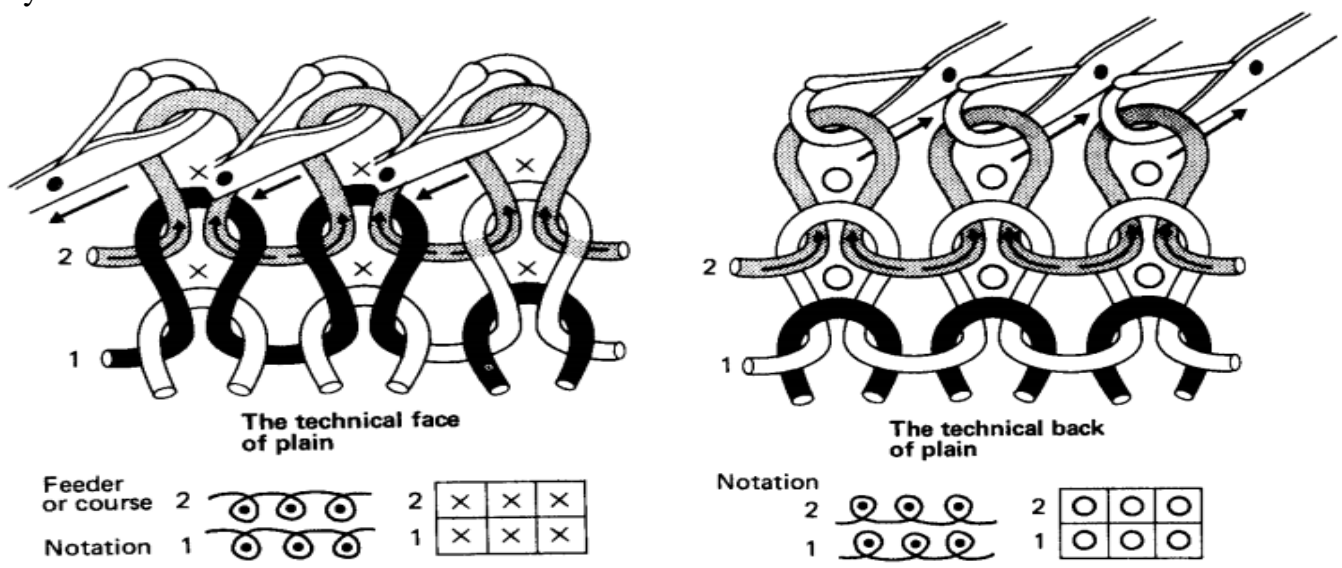

Figure 01: Technical face and back side of single jersey knit fabric [3]

Two major knit fabric properties such as Pilling and Abrasion Resistance were tested to perform this research work. Abrasion resistance and pilling performance are two of the most important mechanical characteristics of fabrics. The resistance of a fabric against the force of friction is known as the abrasion resistance. In general, pilling is a fabric defect observed as small fiber ball or a group consisting of intervened fibers that are attached to the fabric surface by one or more fibers [4].

Pilling is a surface defect of textiles caused by wear, and is considered unsightly. It happens when washing and wearing of fabrics causes loose fibers to begin to push out from the surface of the cloth, and, over time, abrasion causes the fibers to develop into small spherical bundles, anchored to the surface of the fabric by protruding fibers that haven't broken. The textile industry divides pilling into four stages: fuzz formation, entanglement, growth, and wear-off [5]. Pilling normally happens on the parts of clothing that receive the most abrasion in day-to-day wear, such as the collar, cuffs, and around the thighs and rear on trousers[6]. Pilling can seriously compromise a textile's acceptability for consumers, and is the focus of significant industry research. In 
the textile industry, severity of pilling is objectively evaluated using five parameters like pill number, the mean area of pilling; the total area of pilling; contrast, and density [7]. Abrasion resistance is a major factor in determining the lifespan of many textile products. It is influenced by all parts of a fabric's hierarchy: by the fiber, by the yarn structure, and by the webbing construction type. Abrasion is a wear process. Wear is erosion or movement that occurs on a solid surface when it comes into contact with another surface and includes adhesive wear, abrasion, surface fatigue, erosion and fretting wear.

Abrasion resistance' is not described by the Textile Institute, but is defined by ASTM as the resistance to abrasion, usually stated in terms of a number of abrasion cycles. Academics at Leeds University have described abrasion as "the physical destruction of fibers, yarns, and fabrics, resulting from the rubbing of a textile surface over another surface". Abrasion resistance of the textile materials is very complex phenomenon and affected by many factors, mainly classified as follows: Fiber, yarn, fabric properties and finishing processes. Some of these parameters affect fabric surface whereas some of them has an influence on internal structure of the fabrics. An increase in fabrics abrasion resistance generally increases weft tension [8].

\section{Literature Review}

Mechanical characteristics are very important within fabric characteristics. The mechanical characteristics of fabrics generally affect fiber, yarn and fabric characteristics and the finishing process [9]. Pilling rarely effect the actual durability of a fabric but effect adversely in processing as well as to the physical properties of the fabric like appearance, handle etc. [10]. There are many factors, such as the many spinning system, fabric construction and finishing operation, which effect the abrasion resistance and pilling performance. With certain precautions taken in fabric production, the abrasion resistance and pilling performance knit fabrics can be developed positively. Many textile scientists have studied factors that have an effect on pilling and abrasion resistance [11-14].

Frictional or abrasive force is one of the most important factors for the pill information. Other factor remaining unchanged increased in frictional or abrasive force increasing pilling [10]. Betran et al. stated that the pilling tendencies of woolen jersey and rib knit fabrics can be predicted by looking at fiber, thread and fabric properties using artificial neural network [15]. The study by Nergis and Candan included the pilling performance and abrasion resistance of plain knitted fabric from chenille yarns. The results showed that yarn properties (component yarn count, pile length) and laundering or dry cleaning do not influence the pilling performance and abrasion resistance of dry relaxed fabrics, whose component yarns tend to decrease [16].

Omeroğlu \& Ulku can, in his experimental studies, investigated the abrasion resistance and pilling performance of plain weave fabrics made from $100 \%$ cotton ring carded, ring combed and OE rotor spun yarns. He found that the abrasion resistance and pilling performance of fabrics made from OE rotor spun yarns had a maximum value. However, he determined that the abrasion resistance and pilling performance of fabrics made from ring carded spun yarns had a minimum value [17]. Adanur et al. investigated the abrasion resistance of 3/1 cotton twill fabrics made with different warp and weft tension. They concluded that an increase in fabrics abrasion resistance generally increases weft tension [9].

Akaydin studied basic knitted fabrics from ring combed and compact yarns and determined that the abrasion resistance and pilling performance of supreme fabric were lower than interlock fabrics. He ascribed this situation to interlock fabric being more stable, thicker and voluminous than supreme fabric and to the characteristic of knit construction [18].

3.1 Materials

\section{Materials \& Methods}

Sample: 1. Single Jersey (made from carded yarn)

2. Single Jersey (made from combed yarn)

Table 01: Different parameters of two samples.

\begin{tabular}{|l|c|c|}
\hline Type & Single Jersey (Carded yarn) & Single Jersey (Combed yarn) \\
\hline Yarn Count & $30 \mathrm{Ne}(\mathrm{K})$ & $30 \mathrm{Ne}(\mathrm{C})$ \\
\hline Fabric G.S.M & 138 & 133 \\
\hline Stitch Length & $2.77 \mathrm{~mm}$ & $2.77 \mathrm{~mm}$ \\
\hline Machine diameter & $19 \mathrm{inch}$ & 19 \\
\hline
\end{tabular}

\subsection{Methods}

The standard temperate atmosphere for conditioning and testing textiles as defined in ISO 139 has been used. i.e. a temperature $(20 \pm 2)^{\circ} \mathrm{C}$ and a relative humidity $(65 \pm 2) \%$.

In addition to the test apparatus and auxiliary materials specified in ISO 12947-1, a balance, having an accuracy of $1 \mathrm{mg}$ is used. 


\subsubsection{Pilling}

Principle: Specimens are mounted on polyurethane tubes and tumbled randomly in a cork-lined box at a constant rotational speed. Fuzzing and pilling is assessed visual after a defined period of tumbling. Any special treatment of the laboratory sample, i.e. washing, cleaning, has to be agreed upon and shall be stated in the test report. Several apparatuses are used in this test like pill testing box, polyurethane specimen tubes, mounting jig, self-adhesive polyvinyl (PVC) tape, sewing machine, viewing cabinet etc.

Table 02: Assessment of fuzzing and/or pilling.

\begin{tabular}{|c|l|}
\hline Grade & \multicolumn{1}{|c|}{ Description } \\
\hline 5 & No change. \\
\hline 4 & Slight surface fuzzing and/or partially form pills. \\
\hline 3 & $\begin{array}{l}\text { Moderate surface fuzzing and/or moderate pilling. Pills of varying size and density partially covering the specimen } \\
\text { surface. }\end{array}$ \\
\hline 2 & $\begin{array}{l}\text { Distinct surface fuzzing and/or distinct pilling. Pills of varying size and density covering a large proportion of the } \\
\text { specimen surface. }\end{array}$ \\
\hline 1 & $\begin{array}{l}\text { Dense surface fuzzing and/or severe pilling. Pills of varying size and density covering the whole of the specimen } \\
\text { surface. }\end{array}$ \\
\hline
\end{tabular}

\subsubsection{Abrasion resistance}

Principle: A circular specimen is subjected to a defined load and rubbed against an abrasive medium (standard fabric) in a transitional movement tracing a lissome figure. The specimen holder containing the abrasive medium is additionally freely rotatable around its own axis perpendicular to the plane of the specimen. The evaluation of the abrasion resistance of the textile fabric is determined from assessment of the appearance change.

Tests are performed using the mass of the specimen holder and spindle alone at $(198 \pm 2) \mathrm{g}$.

The surface change of the test specimen is assessed and compared with an untested specimen of the same fabric, with the option of using methods:

- Abrasion testing to an agreed number of rubs and assessing whether a surface change has occurred.

- Abrasion testing to an agreed surface change and determination of the test interval in which the surface change has been produced.

Table 03: Test interval for mass loss loading

\begin{tabular}{|c|c|c|}
\hline Test series & $\begin{array}{c}\text { Number of rubs at which } \\
\text { specimen breakdown occurs }\end{array}$ & Determination of mass loss at following numbers of rubs \\
\hline $\mathrm{a}$ & $\leq 1000$ & $100,250,500,750,1000(1250)$ \\
\hline $\mathrm{b}$ & $>1000 \leq 5000$ & $500,750,1000,2500,5000(7500)$ \\
\hline $\mathrm{c}$ & $>5000 \leq 10000$ & $1000,2500,5000,7500,10000(15000)$ \\
\hline $\mathrm{d}$ & $>10000 \leq 25000$ & $5000,7500,10000,15000,25000,(40000)$ \\
\hline $\mathrm{e}$ & $>25000 \leq 50000$ & $10000,15000,25000,40000,50000,(75000)$ \\
\hline $\mathrm{f}$ & $>50000 \leq 100000$ & $10000,15000,25000,40000,50000,75000,100000,(125000)$ \\
\hline $\mathrm{g}$ & $>100000$ & $25000,40000,50000,75000,100000,(125000)$ \\
\hline
\end{tabular}

\section{Experimental Data}

Table 04: Pilling (ISO 12945 - 1)

\begin{tabular}{|c|c|c|c|}
\hline $\begin{array}{c}\text { ICI } \\
\text { After hours }\end{array}$ & $\begin{array}{c}\text { Martindale } \\
\text { Cycle/rubs }\end{array}$ & $\begin{array}{c}\text { Result Grade (Carded } \\
\text { Sample) }\end{array}$ & $\begin{array}{c}\text { Result Grade (Combed } \\
\text { Sample) }\end{array}$ \\
\hline 4 hrs & 14400 & 3 & $3-4$ \\
\hline
\end{tabular}

Table 05: Pilling (ISO 12945 - 2)

\begin{tabular}{|c|c|c|}
\hline $\begin{array}{c}\text { MARTINDAL } \\
\text { CYCLE/RUBS }\end{array}$ & Result Grade (Carded Sample) & $\begin{array}{c}\text { Result Grade } \\
\text { (Combed Sample) }\end{array}$ \\
\hline 125 & $4-5$ & $4-5$ \\
\hline 500 & $4-5$ & $4-5$ \\
\hline 1000 & 4 & 4 \\
\hline 2000 & 4 & 4 \\
\hline 5000 & $3-4$ & $3-4$ \\
\hline 7000 & 3 & 3 \\
\hline 10000 & 2 & 2 \\
\hline
\end{tabular}

Table 06: Abrasion Resistance (ISO 12947 - 2,3,4)

\begin{tabular}{|c|c|c|c|c|}
\hline Yarn Type & Revolution & Color change & Pilling grade & Remark \\
\hline \multirow[t]{2}{*}{ Carded } & 5000 & \multirow[t]{2}{*}{$3-4$} & \multirow[t]{2}{*}{4} & \multirow{2}{*}{$\begin{array}{c}\text { No thread break on hole is } \\
\text { observed. }\end{array}$} \\
\hline & 20000 & & & \\
\hline \multirow[t]{2}{*}{ Combed } & 5000 & \multirow[t]{2}{*}{$3-4$} & \multirow[t]{2}{*}{4} & \multirow{2}{*}{$\begin{array}{l}\text { No thread break on hole is } \\
\text { observed. }\end{array}$} \\
\hline & 20000 & & & \\
\hline
\end{tabular}




\subsection{Pilling (ISO 12945 - 1)}

\section{Result \& Discussion}

\section{Revolution}

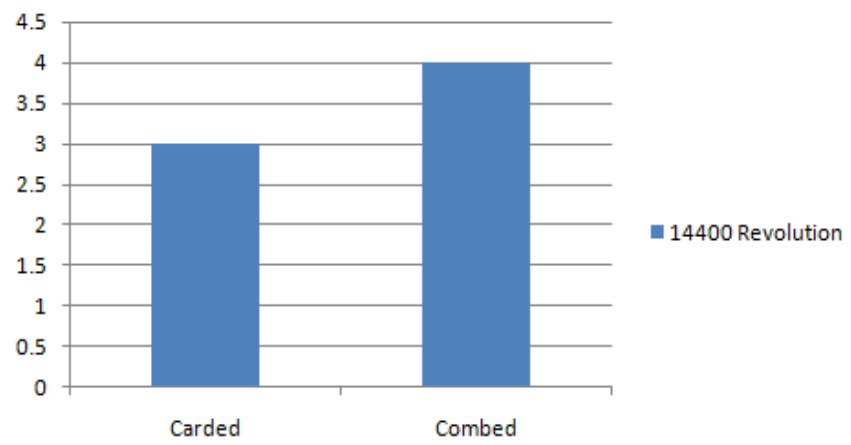

Figure 02: Result of pilling (ISO $12945-1$ )

In (ISO 12945 - 1) method, we examine the pilling effects for carded and combed yarn. We found some variations in the results. Pilling tendency of Combed yarn is lower than Carded yarn. After 4 hours and 14400 revolutions, pilling grade of carded yarn is 3 and combed yarn is 3 to 4 .

\subsubsection{Pilling (ISO 12945 - 2)}

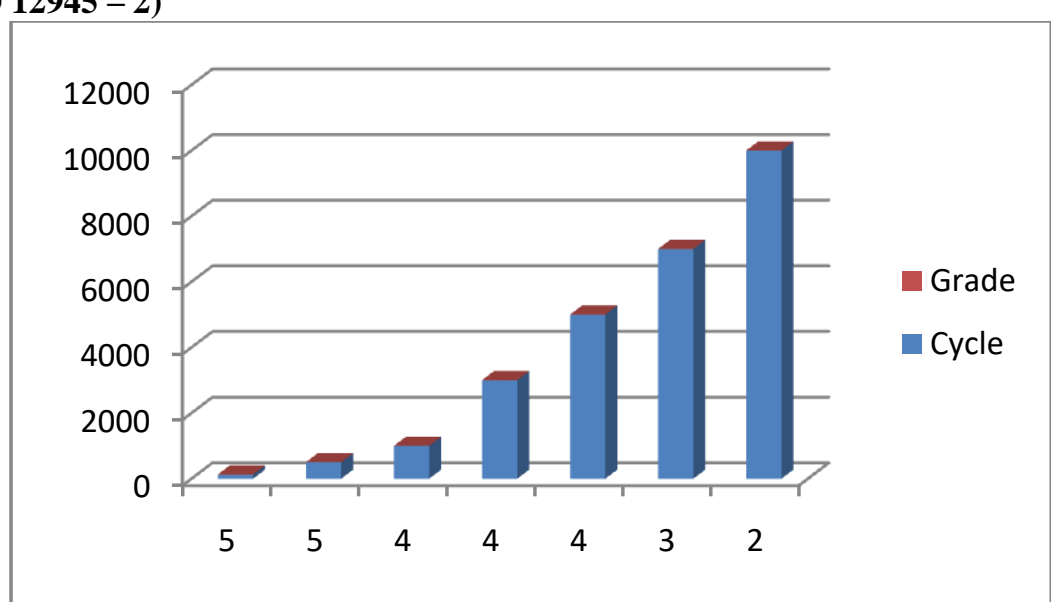

Figure 03: Result of pilling (ISO 12945 - 2)

In (ISO 12945 - 2) methods, we found that pilling tendency of Carded yarn and Combed yarn is same. After 4 hours 125, 500, 1000, 3000, 5000, 7000, 10000 revolutions pilling grade of carded yarn and combed yarn is 5, 5, $4,4,4,3,2$ respectively.

\subsection{Abrasion Resistance (ISO 12947 - 2, 3, 4)}

Abrasion Resistance (ISO 12947 - 2,3,4)

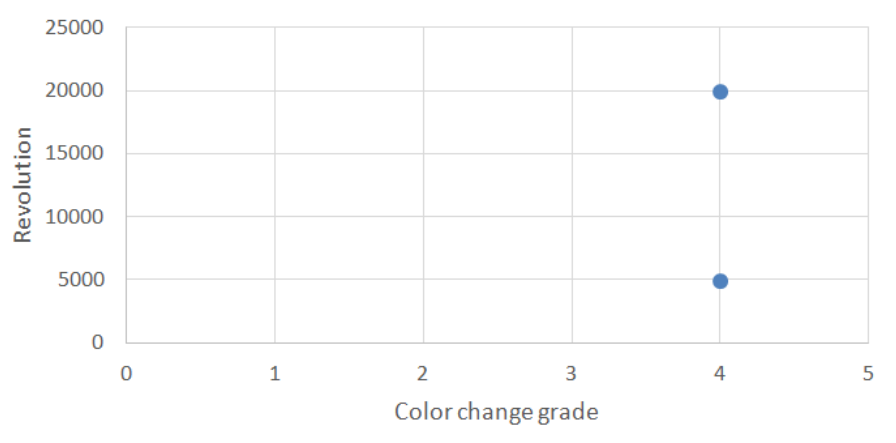

Figure 04: Result of abrasion resistance (ISO 12947 - 2, 3, 4) 
In (ISO 12947 - 2, 3, 4) method, in assessing the abrasion resistance effects we found the same result for both Carded and Combed yarn. After 4 hours 5000, 20000 revolutions, the color change grade for carded and combed yarn is 3 to 4 and pilling grade is 4 .

\section{Conclusion}

In this study, the effect of combed and carded yarn on knit fabric properties especially on pilling and abrasion resistance has been analyzed. This experiment will help the textile technologist to take many important decisions in the factory whether we need to use carded yarn or combed yarn. According to study, it can be concluded that in case of abrasion resistance there will be little bit differences between carded and combed yarn but in case of pilling there will be significant differences. So, it is obvious that the outcome of this study will be beneficial for the textile engineers in selecting the suitable yarn to make the fabric with desired properties.

\section{Acknowledgement}

We would like to give special thanks to Mr. Ariful Islam (Former lab officer, Esquire Group) who conducted all of the tests of this study and also grateful to Esquire Group to give the opportunity to use their textile testing and quality control lab.

\section{References}

[1]. Dr. A. N khan, M.R Chowdhury; 'Principle of Short Staple Spinning' Volume-I, Page -16, Second Edition, ISBN: 978-984-877601-8, Publisher- Books Fair Publications.

[2]. W. Klein, Manual of Textile Technology, Volume-3, Page-122, Edition: 2008

[3]. Knitting Technology, David J Spancer.

[4]. Okur A.; Textile and Engineer, 1994, pp.10-18.

[5]. Shen, Gang, and Xiong Huang (2011). Advanced Research on Electronic Commerce, Web Application, and Communication, Part 1. London: Springer Heidelberg Dordrecht. p. 80. ISBN 978-3-642-20366-4.

[6]. Mehta, Pradip V., and Satish K. Bhardwaj (1998). Managing quality in the apparel industry. New Delhi: National Institute of Fashion Technology and New Age International Publishers.

[7]. Fan, Jintu, and Winnie Wing-man Yu, Winnie Yu, L. Hunte (2004). Clothing appearance and fit: science and technology. Cambridge: Woodhead Publishing Series in Textiles No. 33. pp. 54-60. ISBN 1-85573-745-0.

[8]. Adanur, S. and Gowayed, Y. and Thomas, H. and Ghosh, T., 2000, On-Line Measurement of Fabric Mechanical Properties for Process Control, Auburn University, 196-A09, 7p.

[9]. Greenwood, K., Weaving; Control of fabric structure, Merrow Publishing Co. Ltd., 1975, p.8.

[10]. J.E Booth; Principle of Textile Testing, Third Edition.

[11]. Ahmed M., Slater K.; Journal of Text. Inst.,80, 1989, pp. 279-84. 11

[12]. Alston P. V.; Textile Research Journal,62(3), 1992, pp. 105-108. 12

[13]. Lee W., Dhingra R. C., Lo T. Y., Abbas, M.S.; Journal of Federation of Asian Professional Textile Associations, 3, 1996 , pp.50-58. 13

[14]. Ning P., Zeronian S. H.; Textile Research Journal, 63(1), 1993, pp. 33-43.]. 14

[15]. Özdil N., Özdogan E., Demirel A., ÖktemT., Fibres \& Textiles in Eastern Europe,13(2), 2005, pp. 39-43. 15

[16]. Nergis B. U., Candan C.; Textile Research Journal, 73(12), 2003, pp. 1052-1056. 16

[17]. Can Y.; Fibres \& Textiles in Eastern Europe,16(1), 2008, pp. 81-84. 17

[18]. Akaydin M.; Indian Journal of Fibre \& Textile Research, 34, 2009, pp. 26-30. 18 